\title{
COPAAQIBEAK
}

\section{ASSESSINGTHEOUIRREAKRESPONSE ANDIMPROMNGPRFPAREDNES}




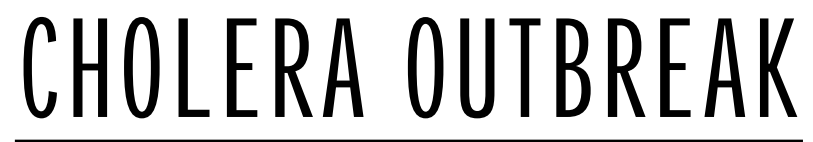

\section{ASSESSINGTHEOUIRREAKRESPONSE ANDIMPROMNGPREPAREDNESS}

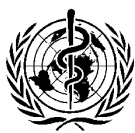

World Health Organization, Geneva 2004 GOBALTASKFOROEONOHOLRACONIROL 
${ }^{0}$ World Health Organization, 2004

All rights reserved.

The designations employed and the presentation of the material in this publication do not imply the expression of any opinion whatsoever on the part of the World Health Organization concerning the legal status of any country, territory, city or area or of its authorities, or concerning the delimitation of its frontiers or boundaries. Dotted lines on maps represent approximate border lines for which there may not yet be full agreement.

The mention of specific companies or of certain manufacturers' products does not imply that they are endorsed or recommended by the World Health Organization in preference to others of a similar nature that are not mentioned. Errors and omissions excepted, the names of proprietary products are distinguished by initial capital letters.

The World Health Organization does not warrant that the information contained in this publication is complete and correct and shall not be liable for any damages incurred as a result of its use. 


\section{Contents}

Introduction

5

Cholera - general

1. Outbreak detection

10

Keywords: early detection - rapid verification and response

2. Outbreak confirmation

Keywords: case definition - laboratory confirmation

3. Organization of the response

.18

Keywords: cholera coordination committee - plan of action

4. Management of the information

.23

Keywords: clarifying rumours - partnership with media

5. Case management: treatment

Keywords: assessment of the patient - rehydration - education

6. Reduction of mortality. 31

Keywords: cholera treatment units - supplies - training of professionals

7. Hygiene measures in health care facilities 36

Keywords: isolation of patients - disinfection - hand-washing

8. Involvement of the community to limit the spread of the disease. 40 Keywords: health education - appropriate messages - cultural acceptability

9. Control of the environment: safe water. 44 Keywords: chlorination - water quality testing - boiling water 
10. Control of the environment: safe food

Keywords: preparation of food - hygiene in marketplaces cooked food

11. Control of the environment: sanitation.

Keywords: improved sanitation - education on hygiene

12. Funeral practices 54

Keywords: hygienic handling of corpses - restrictions on feasts

13. Surveillance

Keywords: information for action - descriptive epidemiology

14. Involvement of international partners.

Keywords: project proposals - coordination of international partners

\section{Appendices}

1. Tool for evaluation .....................................................................................66

2. Outline of the assessment report.....................................................68

3. Essential rules in a cholera treatment unit .........................................70

4. Chlorine dilution according to use..........................................................72

5. Methods for household water treatment ............................................74

6. Key messages for health education ........................................................76

7. Preparation and use of the $1 \%$ chlorine stock solution

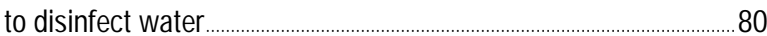

8. Rules for safe preparation of food to prevent cholera .......................82

9. Matrix for coordination of cholera control activities ...........................84

References $\ldots$ 


\section{Introduction}

\section{OBJFCIIVES}

Cholera outbreak response generally focuses on medical aspects that are important for lowering mortality. However, a more comprehensive response is needed to limit the spread of the disease. As the outbreak response is often led by medical professionals, other aspects, such as environmental or communication issues, might tend to be neglected.

This document offers a framework for the assessment of a cholera outbreak response, which will help to:

- provide a comprehensive overview of the outbreak response;

- pinpoint the main strengths and weaknesses of the response;

- improve preparedness for and response to future outbreaks;

- provide accurate recommendations based on WHO official guidelines.

It is intended primarily for:

- technical staff of ministries of health;

- health professionals in WHO country offices;

- consultants responsible for undertaking a cholera outbreak assessment. 
Introduction

1 Detection

2. Confirmation

3. Response

4. Information

5. Treatment

6. Mortality

7. Hygiene

8. Community

9. Water

10. Food

11 Sanitation

12. Funeral

B. Surveillance

14. Partners

A.1

A.2

A.3

A.4

A.5

A.6

A.7

A.8

A.9

\section{WHENCANIT BEUSHD?}

This document can be used at the end of the outbreak, for retrospective evaluation which is essential to plan for improved prevention and response in the future. Additional tools are given in Appendices 1 and 2 to help with the evaluation report.

The document can also be used during an outbreak to check whether any of the aspects of cholera control has been overlooked.

\section{SIRLCIUREOFTHEDOOUMNT}

The document contains a general section on cholera, plus 14 technical sections, each with the following format:

- Keywords reflecting the principal topic(s) covered.

- Assessment of the outbreak listing the questions that should be addressed during the evaluation.

- Useful comments for improved preparedness particularly useful if there are recurrent outbreaks of cholera on a seasonal basis (usually in the rainy season).

- Tips highlighting the main issues relating to cholera outbreaks. 


\section{Cholera - general}

Cholera is a diarrhoeal disease caused by infection of the intestine with the bacterium Vibrio cholerae, either type 01 or 0139. Both children and adults can be infected.

About $20 \%$ of those who are infected develop acute, watery diarrhoea $10-20 \%$ of these individuals develop severe watery diarrhoea with vomiting. If these patients are not promptly and adequately treated, the loss of such large amounts of fluid and salts can lead to severe dehydration and death within hours. The case-fatality rate in untreated cases may reach $30-50 \%$. Treatment is straightforward (basically rehydration) and, if applied appropriately, should keep case-fatality rate below $1 \%$.

Cholera is usually transmitted through faecally contaminated water or food and remains an ever-present risk in many countries. New outbreaks can occur sporadically in any part of the world where water supply, sanitation, food safety, and hygiene are inadequate. The greatest risk occurs in over-populated communities and refugee settings characterized by poor sanitation, unsafe drinking-water, and increased personto-person transmission. Because the incubation period is very short ( 2 hours to 5 days), the number of cases can rise extremely quickly. 
Introduction

1 Detection

2. Confirmation

3. Response

4. Information

5. Treatment

6. Mortality

7. Hygiene

8. Community

9. Water

10. Food

11 Sanitation

12. Funeral

B. Surveillance

14. Partners

A. 1

A. 2

A.3

A.4

A.5

A.6

A.7

A.8

A.9
It is impossible to prevent cholera from being introduced into an area - but spread of the disease within an area can be prevented through early detection and confirmation of cases, followed by appropriate response. Because cholera can be an acute public health problem - with the potential to cause many deaths, to spread quickly and eventually internationally, and to seriously affect travel and trade - a well coordinated, timely, and effective response to outbreaks is paramount.

Response activities should always be followed by the planning and implementation of preparedness activities that will allow future cholera outbreaks to be dealt with more effectively. A strong cholera preparedness plan and programme is the best preparation for outbreaks in countries at risk of cholera, whether or not they have yet been affected, or countries in which seasonal recurrence of the disease may be expected.

\section{NEWSIRAIRGIES: ORAL GHOHRA VACONES}

In the long term, improvements in water supply, sanitation, food safety and community awareness of preventive measures are the best means of preventing cholera, as well as other diarrhoeal diseases. However, WHO is currently evaluating the use of newer tools to complement these traditional measures. Oral cholera vaccines of demonstrated safety and effectiveness have recently become available for use by individuals. Some countries have already used oral vaccine to immunize populations considered to be at high risk for cholera outbreaks. 
Use of these vaccines in both endemic and epidemic situations requires further assessment.

Work is under way to investigate the role of mass vaccination as a public health strategy for protecting at-risk populations against cholera. Issues being addressed include logistics, cost, timing, vaccine production capacity, and criteria for the use of mass vaccination to contain and prevent outbreaks. 


\section{Introduction}

1 Detection

2. Confirmation

3. Response

4. Information

5. Treatment

6. Mortality

7. Hygiene

8. Community

9. Water

10. Food

11 Sanitation

12. Funeral

B. Surveillance

14. Partners

A.1

A.2

A.3

A.4

A.5

A.6

A.7

A.8

A.9

\section{Outbreak detection}

\section{IEMORDS}

EARLY DETECTION - RAPID VERIFICATION AND RESPONSE

\section{ASSESSMFNTOFTHEOUIBREAK}

1. How were the first cases notified to health authorities (through surveillance system, media release or radio announcements, informal sources, other)?

Are the communication channels for reporting cases well established in regions or municipalities?

2. At the beginning, what alerted people to the possibility of an outbreak:

- a sudden occurrence of the disease?

- a persistent increase in reported cases (over a period of more than one week)?

- a sudden increase in the number of cases?

- an abnormal number of deaths?

3. On what basis was it decided that this was an outbreak:

- a single case?

- a cluster of cases?

- case incidence greater than expected (compared with the same period of time in previous years)?

\section{CHOIFRAOUIIREAKRESPONEE}

10 
4. How long did the information take to reach decision-making level from the area where the outbreak occurred? (It should not be more than one week.)

5. What were the first actions taken at the central level:

- telephone call to the affected areas to verify rumours?

- dispatch of a rapid-response team (see tip 1.1)?

- other?

\section{LSFHLCOMMENIS FORIMPROMFPRHPARFDNESS}

According to the way in which health authorities were notified of the outbreak, what conclusions can we draw about the health surveillance system? Is the surveillance system able to detect outbreaks? Is it important to improve detection capacity by including other stakeholders (e.g. private clinics, traditional healers) in the notification process?

Having a special form with key questions might help in quickly differentiating rumours from real outbreaks.

Other sources of information can be used:

- Use journalists as a complementary source for of information on outbreaks of cholera; any information collected through media needs to be confirmed (see section 2).

- Set up a "hot line" with answering machine to encourage people to leave information or questions. 


\section{Introduction}

1 Detection

2. Confirmation

3. Response

4. Information

5. Treatment

6. Mortality

7. Hygiene

8. Community

9. Water

10. Food

11 Sanitation

12. Funeral

B. Survellance

14. Partners

A.1

A.2

A.3

A.4

A.5

A.6

A.7

A.8

A.9

\section{TIPS}

\subsection{ARAPID VFRIHCAIIONAND RESPONSE TEAM}

When an outbreak is suspected, it might be important to send a multidisciplinary team to the field in order to confirm the outbreak and to take the first measures for controlling the spread of the disease.

The team might consist of:

- a physician who will both verify patients' clinical symptoms and train health care workers in good case management;

- a microbiologist who will take stool samples (and environmental samples) for laboratory confirmation of cholera and train health care workers in correct sampling procedure;

- an expert in Information, Education and Communication (IEC) who will assess how the community reacts to cholera and define and disseminate key health education messages;

- an epidemiologist who will assess data collection and surveillance procedures;

- a water and sanitation expert to investigate the possible sources of contamination and start the appropriate treatment of these sources. 
A smaller team may be appropriate. Since it is made up of only one or two specialists, they should adopt a comprehensive approach; they must be aware of the basic elements to be investigated and of which interventions should be implemented first, even if these are not within their technical field of expertise.

\subsection{IMESIIGAIIONOF THE CALSE OF THE OUIRREAK}

Once the cholera outbreak is clinically verified, the following potential "vehicles of transmission" must be investigated so that appropriate control measures can be taken:

- drinking-water that may have been contaminated at source or during transport and storage, or ice made with contaminated water;

- food that may have been contaminated during or after preparation;

- seafood;

- fruits and vegetables. 


\section{Introduction}

1 Detection

2. Confirmation

3. Response

4. Information

5. Treatment

6. Mortality

7. Hygiene

8. Community

9. Water

10. Food

11 Sanitation

12. Funeral

B. Surveillance

14. Partners

A.1

A.2

A.3

A.4

A.5

A.6

A.7

A.8

A.9

\section{Outbreak confirmation}

\section{KEMORDS}

CASE DEFINITION - LABORATORY CONFIRMATION

\section{ASSESSMENTOFTHEOUIRREAK}

1. How was the diagnosis confirmed:

- clinical case definition?

- laboratory confirmation?

- epidemiological suspicion associated with clinical case definition?

2. What case definition was used to collect further information on cases and deaths (see tip 2.1)?

3. In the case of laboratory confirmation, were the collection and the transportation of samples adequate (see tip 2.2 and 2.4)? Did the laboratory use enrichment techniques for the culture of Vibrio cholerae?

4. How long did the laboratory take to provide confirmation?

5. How many samples were taken (see tip 2.3)?

6 . What proportion of samples were positive?

\section{OHOIFRAOUIBREAKIRESPONSE}




\section{USHFULCOMMENISFORIMPROMFDPRFARHDNESS}

In countries where cholera outbreaks follow seasonal patterns, dissemination of the standard case definition to health care workers before the expected "cholera season" may help to increase awareness and ensure adequate diagnosis.

The advance distribution of transport media and rectal swabs in the areas suspected of being affected by cholera is an asset. A national reference laboratory should be designated to supervise the laboratory process - provision of transport media and reagents, training of technicians, monitoring the quality of examinations.

\section{TIIPS}

\section{CASE DEHNIION}

It is most important to ascertain that all patients considered to be cholera cases in fact have the same disease. According to the WHO case definition, a case of cholera should be suspected when:

- in an area where the disease is not known to be present, a patient aged 5 years or more develops severe dehydration or dies from acute watery diarrhoea;

- in an area where there is a cholera epidemic, a patient aged 5 years or more develops acute watery diarrhoea, with or without vomiting.

A case of cholera is confirmed when Vibrio cholerae 01 or 0139 is isolated from any patient with diarrhoea. 
Introduction

1 Detection

2. Confirmation

3. Response

4. Information

5. Treatment

6. Mortality

7. Hygiene

8. Community

9. Water

10. Food

11 Sanitation

12. Funeral

B. Surveillance

14. Partners

A. 1

A. 2

A. 3

A.4

A.5

A.6

A.7

A.8

A. 9

In children under 5 years of age, a number of pathogens can produce symptoms similar to those of cholera, such as ricewater diarrhoea. To maintain specificity, therefore, children under 5 are not included in the case definition of cholera.

\section{IABORAIORY CONHRMAION}

The treatment of dehydrated patients should not be delayed until laboratory testing of samples has been completed. Micro - biological confirmation of Vibrio cholerae by direct observation can be obtained immediately, but it usually takes 2 days to get culture results. It is important to gather information on:

- serogroup of Vibrio (01 or 0139);

- antimicrobial sensitivity patterns.

\section{NMBER OF SAMPIES RFQUIRED}

Laboratory confirmation of the first $10-20$ cases is essential to ascertain that this is a cholera outbreak. It is not necessary to take a sample from every patient with acute diarrhoea, once the cholera outbreak is confirmed: the clinical case definition permits detection of cholera and adequate treatment. However, it may be interesting to take a few samples randomly during the outbreak to make sure that the antimicrobial sensitivity pattern of the pathogen has not changed. Later, collection of about 20 stool samples is necessary to confirm the end of the outbreak. Where cholera is present but not epidemic, it causes fewer than $5 \%$ of all cases of acute diarrhoea.

\section{OHOIFRAOUIBREAKRISPONSE}




\section{SAMPE COHFCIION}

Take stool samples before giving antibiotics to the patient. There are several ways to take samples:

- Fresh stool can be taken (cotton-tipped rectal swab soaked in liquid stool, placed in a sterile plastic bag) and transported quickly (within 2 hours) to the laboratory.

- A transport medium such as Cary-Blair or peptone water allows better conservation of samples (see below for more details).

- Strips of blotting paper or filter paper soaked with liquid stool, placed in sealed tube or plastic bags, with 2 or 3 drops of normal saline $(\mathrm{NaCl} 9 \%)$ so that the specimen remains moist and does not dry out. Refrigeration during transport is not necessary.

Tubes of Cary-Blair transport medium can be stored at ambient temperature for 1-2 years; the medium can be used as long as it does not appear dried out, contaminated, or discoloured.

To use Cary-Blair medium:

- Moisten the swab in sterile Cary-Blair transport medium.

- Insert the swab 2-3 cm through the rectal sphincter and rotate.

- Withdraw the swab and examine it to make sure that it carries some visible faecal material.

- Immediately place the swab in the transport medium, pushing it right to the bottom of the tube.

- Break off and discard the top of the stick touching the fingers.

- Dispatch the sample to reach the laboratory within 7 days; it is not necessary to refrigerate the sample. 


\section{Introduction}

1 Detection

2. Confirmation

\section{Response}

4. Information

5. Treatment

6. Mortality

\section{Hygiene}

8. Community

9. Water

10. Food

11 Sanitation

12. Funeral

B. Surveillance

14. Partners

A.1

A.2

A.3

A.4

A.5

A.6

A.7

A.8

A.9

\section{Organization of the response}

\section{KEMORDS}

CHOLERA COORDINATION COMMITTEE - PLAN OF ACTION

\section{ASSESM HTOFTHEOUIBREAK}

1. Was there a cholera task force or a cholera coordination committee (see tip 3.1) to follow up the outbreak and take decisions? Is this committee multisectoral?

2. What measures have been taken to control the outbreak (see tip 3.2):

- legal decisions (banning of festivals, inspection of food handlers and restaurants, etc.)?

- assistance provided to affected areas (supplies, technical and staff support)?

- health education campaigns?

- timely and adequate mobilization of emergency supplies from national or donor sources?

- information campaigns and use of media?

- training organized (in surveillance or case management)?

\section{OHOIFRAOUIBREAKIRESPONSE}

18 
3. How was the response monitored:

- follow-up of the outbreak through regular epidemiological reports?

- impact of control activities on epidemiological trends?

- field investigation to identify the source of contamination?

4. Who was the person designated to monitor and document control activities?

5. Was a cholera emergency plan of action available?

6. Was there an easy information flow from the affected areas to the control level and vice versa?

\section{USHFULCOMMFNISFORIMPROMFDPRFPARHDNESS}

A cholera coordination committee should be in place in countries were cholera outbreaks are recurrent. This committee may need special funds in order to perform its essential coordination activities. Minutes of meetings are an essential element in monitoring the outbreak response and to ensure that the committee functions correctly. The minutes should detail:

- participants;

- epidemiological situation;

- principal problems raised by decisions taken during previous meetings;

- new decisions and plans for the next meeting. 


\section{Introduction}

1 Detection

2. Confirmation

3. Response

4. Information

5. Treatment

6. Mortality

7. Hygiene

8. Community

9. Water

10. Food

11 Sanitation

12. Funeral

B. Survelllance

14. Partners

A.1

A.2

A. 3

A.4

A.5

A. 6

A.7

A.8

A.9
A cholera emergency plan should list the essential elements of outbreak preparedness and response and should:

- plan logistics (what is available, what is needed);

- plan staff responsibilities (reassignment of staff according to needs, decision on who is responsible at each level);

- ensure availability of financial support for preparation and response (costs of the investigation and the response, sources of funding);

- plan for implementation of the control measures (what should be done, when and who should do it, the resources that are needed and available);

- plan for providing safe water and ensuring safe disposal of excreta, and for education campaigns (materials, methodology, staff). 
- collection and reporting of information on cholera cases and deaths;

- organization of any relevant training;

- procurement storage and distribution of required supplies;

- implementation, supervision, and monitoring and evaluation of control activities.

The cholera coordination committee should meet frequently (at least once a week) during the outbreak period. Specific funds for the emergency need to be available to implement decisions taken by the committee. The committee should receive regular updates on the epidemiological situation. The lead organization of this committee must be clearly designated.

Depending on the size of the country and on its health services structure, similar committees may be created at sub-national or more peripheral levels.

\subsection{FIRST SIFPS TO CONIROLAOHOHRAOUIRREAK}

When the first report of a suspected cholera case is received, the first step is to confirm the outbreak, after which the following activities should be performed (the order may vary according to the situation):

- convene the cholera coordination committee;

- make an inventory of available essential supplies;

- inform the public, neighbouring districts, and the media;

- conduct training if needed;

- set up temporary treatment centres if needed; 
Introduction

1 Detection

2. Confirmation

3. Response

4. Information

5. Treatment

6. Mortality

7. Hygiene

8. Community

9. Water

10. Food

11 Sanitation

12. Funeral

B. Surveillance

14. Partners

A.1

A.2

A.3

A.4

A.5

A.6

A.7

A.8

A.9
- collect, report, and analyse data on cases, deaths, and control activities; document the epidemic; provide feedback and adapt interventions;

- implement measures to control the spread of the disease (disinfection of water sources, food safety measures);

- conduct health education campaigns;

- ask for additional help;

- monitor and evaluate control measures. 


\section{Management of the information}

\section{KEMORDS}

CLARIFYING RUMOURS - PARTNERSHIP WITH MEDIA

\section{ASSESSMENTOFTEOUIRREAK}

1. Was there a strategy to disseminate accurate information promptly rather than respond to rumours (see tip 4.1)?

2. Did the involvement of the media contribute constructively to control of the outbreak (see tip 4.2)?

3. Was a spokesperson in the ministry of health designated (see tip $4.3)$ ?

4. Was there a good balance between public service announcements and news (see tip 4.4)?

5. Was there any procedure for assessing the impact and spread of information? 


\section{Introduction}

1 Detection

2. Confirmation

3. Response

4. Information

5. Treatment

6. Mortality

7. Hygiene

8. Community

9. Water

10. Food

11 Sanitation

12. Funeral

B. Survellance

14. Partners

A.1

A.2

A-3

A.4

A.5

A.6

A.7

A.8

A.9

\section{USHFUCOMMENISFRIMPROME PRHPARHDNESS}

Before the outbreak, responses should be prepared to the most common questions about the disease and the preventive measures; epidemiological data from previous years should be available.

It is important to ensure an open flow of information from the beginning of the outbreak, to prevent the spread of misleading rumour.

\section{TIIPS}

\subsection{Avat rumours}

Avoid rumour and panic by maintaining a very open flow of information - rumours spread easily when information is incomplete or delayed.

\subsection{EALUAIONOF MEIAINOMEMEN}

Did involvement of the media:

- provide information to people within and outside the affected area? 
- provide information in the appropriate language?

- provide information through the appropriate channel (radio, press, television)?

- provide the right type of information, with the right frequency?

\subsection{SPONSPPFRSON}

When an outbreak starts, designate a single spokesperson who will be the focal point for dealing with the media. Plan regular press releases and conferences.

\subsection{BUANGE BEIWEPNPUBICANOUNCENN AND NEMS}

The kind of information to be disseminated will depend on the levels of the media local, national, or international. Public health authorities are generally interested in using the media to provide information on preventive and control measures, i.e. public service announcements, while journalists may focus on spreading news. A balance between the two interests should be established by negotiation. 


\section{Introduction}

1 Detection

2. Confirmation

3. Response

4. Information

5. Treatment

6. Mortality

7. Hygiene

8. Community

9. Water

10. Food

11 Sanitation

12. Funeral

B. Surveillance

14. Partners

A.1

A.2

A-3

A.4

A.5

A.6

A.7

A.8

A.9

\section{Case management: treatment}

\section{KEMMORIDS}

ASSESSMENT OF THE PATIENT - REHYDRATION - EDUCATION

\section{ASSESSMENTOFTHEOURREAK}

1. Were flowcharts illustrating proper management of cholera cases prepared and available to health care workers?

2. Did the flowcharts provide clear information on how to assess dehydration stage and did they provide clear information on the treatment protocol to apply according to the status of the patient (see tips 5.1 and 5.2)?

3. Were antibiotics reserved for severe cases only? Did the patients receive treatment other than rehydration and recommended antibiotics? Was the antibiotic therapy based on antimicrobial resistance patterns (see tip 5.3)?

4. Were patients and their families informed of the preventive measures to take at household level (see tip 5.4)? 
5. Were the cholera patients isolated from other patients (with special latrines)?

6. Were the health care workers aware of the hygienic measures necessary to avoid contamination (hand-washing, isolation ward)?

\section{USHFUCOMMFNIS FORIMPROMFDPRPARHDNES}

Training of health workers is an essential element for preparedness, especially in high-risk areas.

Emergency supply needs should be evaluated in the light of the particular situation:

- likely attack rate in refugee camps, with high-risk populations (because of malnutrition), is $5-8 \%$;

- in open settings, an attack rate of $0.2 \%$ might be used;

- in rural communities of 5000 people or less, the attack rate might reach $2 \%$.

Emergency stocks of basic supplies should be prepared so that they can be mobilized quickly. 


\section{Introduction}

1 Detection

2. Confirmation

3. Response

4. Information

5. Treatment

6. Mortality

\section{Hygiene}

8. Community

9. Water

10. Food

11 Sanitation

12. Funeral

B. Surveillance

14. Partners

A.1

A.2

A-3

A.4

A.5

A. 6

A.7

A.8

A.9

\subsection{RHMDRAIION}

Rehydration with replacement of electrolytes lost is the mainstay of cholera treatment. According to the dehydration stage $(A, B$, $C)$, the patient should receive different rehydration therapy (oral or intravenous fluids). Oral rehydration solution (ORS) should be used during and after IV therapy. Surveillance of the patient is crucial during the early stage of treatment.

Dehydration

Signs

stage

Severe

Lethargic, unconscious, floppy

Very sunken eyes

Drinks poorly, unable to drink

Mouth very dry

Skin pinch goes back very slowly

No tears (only for children)
Restless and irritable Sunken eyes

Dry mouth

Thirsty, drinks eagerly

Skin pinch goes back slowly

No tears (only for children)
Treatment IV therapy + antibiotics + ORS

\begin{tabular}{lll}
\hline Mild & Restless and irritable & ORS + \\
& Sunken eyes & very close \\
& Dry mouth & surveillance \\
& Thirsty, drinks eagerly & \\
& Skin pinch goes back slowly & \\
& No tears (only for children) & \\
&
\end{tabular}

No

dehydration None of the above signs

ORS at home 


\subsection{INIRAMNOUS THFAPY FOR SEYRE CASES}

Ringer's lactate is the preferred IV fluid. Normal $(0.9 \%)$ saline or halfnormal saline with $5 \%$ glucose can also be used, but ORS solution must be given at the same time to replace the missing electrolytes. Plain glucose solution is not effective in rehydrating cholera patients.

When IV rehydration is not possible and the patient cannot drink, ORS solution can be given by nasogastric tube. However, nasogastric tubes should not be used for patients who are unconscious.

\subsection{ANIIHOIICS}

They should be given only in severe cases, to reduce the duration of symptoms and carriage of the pathogen.

Antimicrobial resistance is increasing. In most countries Vibrio cholerae is resistant to co-trimoxazole; in some settings it has also developed resistance to tetracycline. The laboratory should be asked about patterns of resistance of the strain at the beginning of and during the outbreak: antibiotic sensitivity to antibiotics may return after a certain period.

Mass chemoprophylaxis is not effective in controlling a cholera outbreak.

Selective chemoprophylaxis (one dose of doxycycline) may be useful for members of a household who share food and shelter with a cholera patient. However, in societies where intimate social mixing and the exchange of food between households are common, it is difficult to identify close contacts. Nevertheless, chemoprophylaxis may be useful when a cholera outbreak occurs in a closed population, such as a prison. 
Introduction

1 Detection

2. Confirmation

3. Response

4. Information

5. Treatment

6. Mortality

7. Hygiene

8. Community

9. Water

10. Food

11 Sanitation

12. Funeral

B. Survellance

14. Partners

A.1

A.2

A. 3

A.4

A. 5

A.6

A.7

A.8

A.9

\subsection{HEATHEDCAIION}

The most important messages to prevent the family from being contaminated are:

- Wash your hands after taking care of patients touching them, their stools, their vomits, or their clothes.

- Beware of contaminating the water source by washing patients' clothes in the water. 


\section{Reduction of mortality}

\section{KHMORDS}

CHOLERA TREATMENT UNITS - SUPPLIES - TRAINING OF PROFESSIONALS

\section{ASSESSMFNTOFTHEOUIBREAK}

1. How has the case-fatality rate (CFR) been calculated? Was there any risk of bias (see tip 6.1)?

2. Was the CFR over $1 \%$ ? Was there any obvious reason to explain this CFR:

- low accessibility of health care facilities or cholera camps?

- inconsistent case management?

- underlying factors such as malnutrition?

- important contamination?

3. Have professionals been trained to manage patients with cholera (see tip 6.2)?

4. Were appropriate IV fluids, oral rehydration salts (ORS), and antibiotics available?

5. Have special cholera treatment units (CTUs) been set up in order to provide quick treatment to cholera patients and to avoid overburdening other hospital wards (see tip 6.3)? 


\section{Introduction}

1 Detection

2. Confirmation

3. Response

4. Information

5. Treatment

6. Mortality

\section{Hygiene}

\section{Community \\ 9. Water}

10. Food

11 Sanitation

12. Funeral

B. Surveillance

14. Partners

A.1

A.2

A-3

A.4

A.5

A.6

A.7

A.8

A.9
6. Was there adequate surveillance of patients with severe cholera (pulse, dehydration symptoms, respiration, fever, urine) (see tip 6.4)?

7. Were the cholera treatment units and oral rehydration therapy (ORT) corners accessible? Were there any geographical limitations on accessibility or cultural, linguistic, or economic barriers?

\section{USFFULCOMMNISFORIMPROMED PRHPARHDNES}

At every health care facility that might have to deal with cases of cholera, sufficient supplies should be in position to cover the first few days before the arrival of more supplies. These "pre-position" supplies should include both IV fluids and ORS - most patients can be cured with ORS alone.

A needs assessment, including the inventory of supplies available and needed, should be completed before the cholera season.

Health professionals need specific training to treat cholera patients successfully, plus regular refresher courses. A plan should be established to achieve the goal of training $90 \%$ of the health care workers. 


\section{TIPS}

\subsection{CASE-FATIITY RAIE (QRR)}

A rate (see 13.2) of greater than $1 \%$ is generally considered to be high, but in rural areas with very poor accessibility to health care the rate can be higher (sometimes above 20\%). If the CFR exceeds $5 \%$, an investigation should be conducted and appropriate corrective action taken. High CFR may be the result of bias (e.g. underestimation of the number of cases, including deaths from other causes) or of inadequate case management.

\subsection{STAFF INGHOFFA TREAIMENT UNIS}

Cholera treatment units can be specific wards in hospitals or special units set up to treat cholera patients in an emergency situation. During the outbreak, cholera treatment units must be functional 24 hours a day. A plan for rotation of staff therefore needs to be established.

If there are too few personnel with appropriate training, health care workers who have previous experience of cholera outbreaks or who have received adequate training should be mobilized to provide on-site training and supervision of the less experienced personnel.

\subsection{ORTCORNR}

The community should be taught about the importance of starting ORS early and attending health centres quickly. Where health care facilities 


\section{Introduction}

1 Detection

2. Confirmation

3. Response

4. Information

5. Treatment

6. Mortality

7. Hygiene

8. Community

9. Water

10. Food

11 Sanitation

12. Funeral

B. Survellance

14. Partners

A.1

A.2

A.3

A.4

A.5

A. 6

A.7

A. 8

A.9 are less accessible, oral rehydration treatment corners (ORT corners ) should be established throughout the area for low and moderate dehydration. The people should be informed about the CTU to which cases of severe cholera can be referred.

In urban settings

CTUs for severe cases must be clearly identified. ORT corners for mild cases must be available and accessible to the population. Case records are important in both settings for calculating attack rate and for providing supplies accordingly.

In semi-urban or rural settings

Access to health care facilities is a problem and it is important to decentralize the CTU. Active case-finding in communities has to be encouraged in order to locate the new outbreak focus as soon as possible. The population is often mobile and the spread of disease difficult to control. The location of treatment units (CTUs and ORT corners) should be selected according to the attack rate. In isolated health care facilities provision of supplies and drugs to treat the first 20-30 patients should be part of preparedness measures. 


\subsection{SURMEIIANCE OF PAIIFNIS WIHSEVRE GHOIEA}

Surveillance and regular reassessment of patients for the following are crucial:

- pulse;

- dehydration signs;

- number and appearance of stools;

- respiratory rhythm;

- temperature (cholera usually provokes hypothermia if the temperature is high there may be associated pathology, e.g. malaria);

- urine (present or not);

- state of consciousness.

Complications - pulmonary oedema if excessive IV fluid has been given; renal failure if too little IV fluid is given; and hypoglycaemia and hypokalaemia in children with malnutrition rehydrated with Ringer lactate only. 


\section{Introduction}

1 Detection

2. Confirmation

3. Response

4. Information

5. Treatment

6. Mortality

\section{Hygiene}

8. Community

9. Water

10. Food

11 Sanitation

12. Funeral

B. Surveillance

14. Partners

A.1

A.2

A-3

A.4

A.5

A.6

A.7

A.8

A.9

\section{Hygiene measures in health care facilities}

\section{KHMORDS}

ISOLATION OF PATIENTS - DISINFECTION - HAND-WASHING

\section{ASSESSMFNTOFTHEOUIBREAK}

1. Were the cholera treatment units located close to the most affected communities?

2. Were there hand-washing facilities in the cholera treatment centre? Were the patients' relatives washing their hands every time they leave the centre?

3. Were the cholera treatment units organized in four areas - selection and observation, hospitalization, convalescent room for ORS treatment, neutral area (for kitchen, stocks of material, etc.)?

4. Were measures in place for the safe disposal of excreta and vomit? Were there special latrines for cholera patients who can walk, separated from latrines used by the rest of the patients? 
5. Was there enough water to cover the daily needs of patients ( 50 litres/person)?

6. Were buckets, latrines, clothes, and bedding properly disinfected (see tip 7.3)?

7. Were cholera cots available?

\section{USHFULCOMMENISFORIMPROMFDPRPARFDNESS}

Some supplies (buckets, cholera cots, disinfectants, rubber gloves, etc.) are essential for cholera treatment units (CTU) in addition to the supplies needed to treat patients.

In refugee camps where there is no health care facility, a CTU can be set up using tents. During outbreaks in open communities, the CTU might be established inside the health care facility or in another community building, e.g. a school, if the health centre is too small to ensure isolation of the cholera patients.

Cholera treatment units should be ready before an outbreak occurs. This necessitates identification of suitable sites, pre-position of supplies, stocks of drugs and other material, and organization of patient flow. Individual job descriptions for personnel in CTU should be prepared in advance. 


\section{Introduction}

1 Detection

2. Confirmation

3. Response

4. Information

5. Treatment

6. Mortality

\section{Hygiene}

\section{Community}

9. Water

10. Food

11 Sanitation

12. Funeral

B. Survellance

14. Partners

A.1

A.2

A-3

A.4

A.5

A.6

A.7

A.8

A.9

\subsection{Goura treatment UNT (CIU)}

The organization of the CTU is meant to offer the best care to patients but also to protect other people from contamination. Fences around the CTU are often necessary to reduce the number of visitors.

\subsection{FunCIIONS TO BE ENSURED INTHECIU}

- Classification - assessment

- register patients;

- assess the dehydration status (A, B, C).

- Treatment

- treatment wards (observation, hospitalization, convalescent room);

- pharmacy and store;

- ORS preparation area.

(Note: The use of ORS is so important that it is recommended that one person be in charge of preparing and encouraging the use of ORS.)

- Patient care

- rehydration;

- hygiene;

- feeding. 
- Prevention and hygiene

- kitchen for food preparation;

- water treatment;

- preparation of chlorine solution;

- clothes washing facilities, laundry.

- Health education

- health education activities inside the CTU and at patient's home by community worker teams;

- active case-finding in the refugee camp/villages.

- Waste and environment

- safe waste disposal (incinerator, dustbins);

- cleaning and disinfection of the CTU;

- morgue.

- Security

- watchman for information and patient flow control;

- fences;

- protection of stocks (food, drugs, supplies).

\subsection{DSINFCIIONOF PAIIFN'S BFDINGAND GOIHNG}

Patient's bedding and clothing can be disinfected by stirring them for 5 minutes in boiling water. Bedding including mattresses can also be disinfected by thorough drying in the sun (see also Appendix 4). 


\section{Introduction}

1 Detection

2. Confirmation

\section{Response}

4. Information

5. Treatment

6. Mortality

\section{Hygiene}

8. Community

9. Water

10. Food

11 Sanitation

12. Funeral

B. Surveillance

14. Partners

A.1

A.2

A.3

A.4

A. 5

A.6

A.7

A.8

A.9

\section{Involvement of the community to limit the spread of disease}

\section{KEMMORDS}

HEALTH EDUCATION - APPROPRIATE MESSAGES - CULTURAL ACCEPTABILITY

\section{ASSESSMENTOFTHEOUIBREAK}

1. Was health education an important part of the outbreak response (see tip 8.1)?

2. Were the messages spread illustrated by practical demonstrations (e.g. chlorination of water, preparation of ORS)?

3. Were the messages elaborated with the community?

4. Were the messages disseminated through community or religious leaders or through any channel that reaches the maximum of people with greatest impact on their behaviours?

5. Were the messages adapted to local cultural beliefs about the disease and to the capacity for implementing control measures in the community (e.g. if soap is unavailable, have ashes been recommended for washing hands)?

6. Have efforts been made to encourage the use of latrines? 
7. Was there active case-finding in the community (see tip 8.2)?

8. Were education messages given to the patients and their relatives in health care facilities?

9. Were health care workers able to disseminate the appropriate messages (see tip 8.3)?

\section{USHFUCOMMFNISFORIMPROMFDPRFPARFDNESS}

In advance of the cholera season, it is valuable to organize focus group discussions in high-risk communities in order to identify gaps in knowledge and the kind of reinforcement needed.

It is important to check whether soap and chemicals to treat water are available and affordable.

Most of educational messages are technically good but difficult to implement. If soap, chemicals for water treatment are not available, alternative solutions should be found to ensure basic hygiene practices to limit cholera transmission (e.g. lime juice added to water, beverage or other foods have the ability to inactivate V. cholerae).

Assessment of the impact of the messages used previously helps to improve communication with communities.

Health education should continue throughout the year with intensification before the cholera season. 


\section{Introduction}

1 Detection

2. Confirmation

3. Response

4. Information

5. Treatment

6. Mortality

7. Hygiene

8. Community

9. Water

10. Food

11 Sanitation

12. Funeral

B. Survelllance

14. Partners

A.1

A.2

A. 3

A.4

A. 5

A. 6

A.7

A.8

A.9

\section{HEATHEDCAIIONCAMPAIGNDURING OUIBREAK}

An epidemic of cholera can be more quickly controlled when the public understands how to help to limit the spread. Health education is crucial to ensure the participation of the community.

- Select the best way to disseminate messages to the community:

- communication through radio, posters, talks, etc.

- in the local language.

- Give clear information but not too many messages.

- Adapt messages to the social, cultural, and economic circumstances of the community and to its ability to cope with a change of behaviour (for example, chlorine or soap may not be affordable in poor communities).

- Organize talks in places where people are usually waiting (health care facilities, hairdressers, etc.).

\section{ACIIECASE-HNDING}

If possible, active case-finding in communities should be organized to allow:

- detection of cholera patients at an early stage of the disease;

- advice to be given to family members and the community about protecting themselves from contamination. 


\subsection{KEY MESAAES TOGME TO THECOMMNIY}

- Come to the health care facility as soon as possible in case of acute watery diarrhoea.

- Start drinking ORS at home and during travel to the health care facility.

- Wash your hands before cooking, before eating, and after using the toilet.

- Cook food.

- Drink safe water. 


\section{Introduction}

1 Detection

2. Confirmation

3. Response

4. Information

5. Treatment

6. Mortality

\section{Hygiene}

8. Community

9. Water

10. Food

11 Sanitation

12. Funeral

B. Surveillance

14. Partners

A.1

A.2

A-3

A.4

A.5

A.6

A.7

A.8

A.9

\section{Control of the environment: safe water}

\section{KHMORDS}

CHLORINATION - WATER QUALITY TESTING - BOILING WATER

\section{ASSESSM NTOFTHEOUIBREAK}

1. Have the different sources of contaminated water been identified (see tip 9.1)?

2. Have these sources been disinfected during the outbreak?

3. If wells were chlorinated, was there regular monitoring of residual chlorine (see tip 9.2)?

4. What measures were recommended to avoid contamination of water (see tip 9.3)?

5. Where chlorination of a water source was not possible, was there any programme to ensure safe drinking-water at household level (see tip 9.4)?

6. Were chemicals for water disinfection (chlorine compounds) available in the local market at affordable prices?

7. Was there any system for providing safe water to high-risk communities during the outbreak? 
8. Did the population receive a supply of at least 20 litres of safe water per day per person?

9. Were health workers properly trained to teach local people about hygiene and disinfection techniques?

10. Was the community informed about preventing water contamination?

\section{USHFUCOMMFNISFORIMPROMFDPRFPRHDNES}

It takes time for people to change their behaviour. Messages that ensure acceptance of household water treatment and community participation are therefore crucial and must be relayed continually, not just during the outbreak.

A good inventory of all water sources, obtained through sanitary surveys, is useful for identifying potential risks of contamination.

Emergency provisions should include extra stocks of chemicals, standby power generators and emergency prefiltration storage/sedimentation capacity. 


\section{Introduction}

1 Detection

2. Confirmation

3. Response

4. Information

5. Treatment

6. Mortality

7. Hygiene

8. Community

9. Water

10. Food

11 Sanitation

12. Funeral

B. Surveillance

14. Partners

A.1

A.2

A.3

A.4

A.5

A.6

A.7

A.8

A.9

\subsection{THPE F ACCESS TO DRINAING-MIFR}

There are various types of access to drinking-water: household connection, public standpipe, borehole, protected dug well, protected spring, rainwater collection, unprotected well, vendor, tanker truck. The drinking-water might be contaminated where there is contact with:

- hands and bodies of people who have cholera although show no symptoms;

- contaminated articles such as buckets, cups, clothes;

- faecal material (e.g. by infiltration into wells when the latrines are situated less than 30 metres away from the wells).

The risk of water contamination varies according to the type of access to drinking-water.

\subsection{CONIAMNAIFD WHIS}

- Unprotected water sources are very often contaminated. Arrangements should be made for the protection of water sources as an important measure for reducing the risk of contamination.

- Treatment of the source may be the best way to prevent the spread of cholera in the community. In emergencies, a free residual chlorine of about $0.5 \mathrm{mg} /$ litre is advisable (see Appendix 7).

\section{CHOIFRAOUIIREAKRESPONEE}


- When the water source is too turbid it should be filtered before disinfecting.

- Alternatively, filtration and chlorination could be done at household level.

\subsection{Promsionof SAF DRINANG-MIIR}

- The conditions and practices of water collection and storage contribute to the safety of household water.

There is evidence that storage in a narrow-mouthed vessel with a protected dispenser (spigot, spout) is much safer than storage in a wide-mouthed vessel. Drinking water should be kept in a clean covered pot or bucket. It is better to pour the water from the container than to use a potentially contaminated article (e.g. cup without handle) to retrieve the water.

- Different chlorine concentrations are needed according to water use - for drinking, washing of clothes and hands, disinfecting buckets/ utensils (see Appendix 4).

\subsection{HOSFHOW WIIRR TREAIMENT}

Various methods of household water treatment are available: boiling, chlorinating, storage in improved vessels, solar disinfection with UV + heat, UV disinfection with lamps, chemical coagulation-filtration + chlorine disinfection (see Appendix 5). 


\section{Introduction}

1 Detection

2. Confirmation

3. Response

4. Information

5. Treatment

6. Mortality

7. Hygiene

8. Community

9. Water

10. Food

11 Sanitation

12. Funeral

B. Survellance

14. Partners

A.1

A.2

A-3

A.4

A.5

A.6

A.7

A.8

A.9

\section{Control of the environment: safe food}

\section{KEMMORDS}

FOOD PREPARATION - HYGIENE IN MARKETPLACES - COOKED FOOD

\section{ASSESSM NNTOFTHEOUIRREAK}

1. Was the supply of water adequate for street food vendors (acceptable quality and sufficient quantities for drinking, washing food and hands, cleaning utensils)?

2. Was there any regulation to ensure that minimum standards of hygiene were observed by food handlers during the outbreak? Was the inspection of food handling practices effective?

3. Were street sales stopped during the outbreak? Have restau -rants been closed?

4. Is there any regulation to ensure minimum levels of hygiene for food products in the marketplace?

5. Are any local dishes made with raw seafood (particularly crustaceans and other shellfish) or raw fruit or vegetables (see tip 10.1)? 
6. Are food handlers who sell raw or partially processed animal products for immediate consumption required to display a sign that informs the public of the increased health risk associated with consuming such food?

7. Are latrines and hand-washing facilities available in marketplaces?

\section{USFFUCOMMFNISFORIMPROMEDPRFPARFDNESS}

Special attention must be paid to food safety at social gatherings marketplaces, funerals, etc. (see Appendices 6 and 8).

\section{TIPS}

\subsection{COMMONSOURCES OF INFCIION}

- Drinking-water that has been contaminated at its source (e.g. by faecally contaminated surface water entering an incompletely sealed well), during transport and/or supply, or during storage (e.g. by contact with hands soiled by faeces).

- Ice made from contaminated water.

- Cooking utensils washed in contaminated water. 


\section{Introduction}

1 Detection

2. Confirmation

3. Response

4. Information

5. Treatment

6. Mortality

7. Hygiene

8. Community

9. Water

10. Food

11 Sanitation

12. Funeral

B. Surveillance

14. Partners

A.1

A.2

A.3

A.4

A.5

A.6

A.7

A.8

A.9

- Food contaminated during or after preparation. Moist foods (e.g. milk, cooked rice, lentils, potatoes, beans, eggs, and chicken), contaminated during or after cooking/preparation and allowed to remain at room temperature for several hours, provide an excellent environment for the growth of Vibrio cholerae.

- Seafood, particularly crustaceans and other shellfish, taken from contaminated water and eaten raw or insufficiently cooked or contaminated during preparation.

- Fruit and vegetables grown at or near ground level and fertilized with night soil, irrigated with water containing human waste, or "freshened" with contaminated water, and then eaten raw, or contaminated during washing and preparation.

\subsection{Amimining Foods}

Acidifying foods with lemons, tomatoes, yoghurt, and fermented milk helps to inhibit the growth of Vibrio cholerae.

\subsection{INFANT HFING}

Breastfeeding should be continued while a child has cholera. 


\section{Control of the environment: sanitation}

\section{KEMMORDS}

IMPROVED SANITATION - EDUCATION ON HYGIENE

\section{ASSESSMENTOFTHEOUIRRRAK}

1. What percentage of the population was served with improved sanitation facilities (see tip 11.1)?

2. Was there a good system in place for excreta management and disposal during the outbreak (latrine emptying and sludge removal from septic tanks)?

3. Were the sanitation facilities vulnerable to flooding or other natural disasters?

4. Could the sanitation facilities potentially contaminate any drinkingwater sources?

5. Was consideration given to providing sanitation services for high-risk communities during the outbreak (see tip 11.2)?

6. Were health workers properly trained to teach local people about good hygiene behaviours (see tip 11.3)? 


\section{Introduction}

1 Detection

2. Confirmation

3. Response

4. Information

5. Treatment

6. Mortality

7. Hygiene

8. Community

9. Water

10. Food

11 Sanitation

12. Funeral

B. Survellance

14. Partners

A.1

A.2

A-3

A.4

A. 5

A.6

A.7

A. 8

A.9

\section{USFFUCOMMENISFORIMPROMED} PRHPARHDNES

A good inventory of existing sanitation facilities (improved and not improved) should be compiled to evaluate the disease transmission risks.

Hygiene behaviour is a key element in sanitation programmes. Sound sanitation practices such as hand washing with soap, safe disposal of children's faeces, and use of sanitary facilities for defecation are crucial to avoid the spread of disease.

\section{TIIPS}

\subsection{IMPROMEMENT OF SANTAIION}

The population should have access to an improved sanitation facility, such as connection to a public sewer, connection to a septic tank, pour-flush latrine, simple pit latrine, and ventilated improved latrine.

Facilities such as bucket latrines, public or shared latrines, and trenches should be replaced as soon as possible by improved sanitation facilities. 


\subsection{IMOMNG THECOMMNIY}

The community should be involved in all phases of implementation of on-site sanitation projects. Without their participation and involvement there is a risk of misuse or non-use of the sanitation facilities.

\subsection{SANIATIONAND HEATH}

The links between sanitation, water supply, and health are directly affected by hygiene behaviour. The health benefits of access to sanitation services will not be realized without good hygiene behaviour (WHO, 1996).

Sanitation facilities should be hygienic so that they do not endanger the health of the users and the community as a whole. 


\section{Introduction}

1 Detection

2. Confirmation

3. Response

4. Information

5. Treatment

6. Mortality

\section{Hygiene}

8. Community

9. Water

10. Food

11 Sanitation

1. Funeral

B. Surveillance

14. Partners

A.1

A.2

A.3

A.4

A.5

A.6

A.7

A.8

A.9

\section{Funeral practices}

\section{KEMORDS}

HYGIENIC HANDLING OF CORPSES - RESTRICTION ON FEASTS

\section{ASSESSM HNT OFTHEOUIRREAK}

1. Were there any official recommendations with regard to funeral practices, such as funeral gatherings, ritual washing of the dead, or funeral feasts? How has information on this been disseminated?

2. Were funeral organizers aware of the risk and of the control measures that should be implemented to prevent contamination (see tip 12.1)?

3. Were communities aware of what to do with cholera patients who died at home (see tip 12.2)?

4. Were health care workers, especially in cholera camps, well trained in handling corpses (see tip 12.2)? 


\section{LSFFUCOMMENISFORIMPROMEDPRHPARHDNESS}

Before the cholera season, a simple list of the main recommendations should be given to people who may handle corpses.

\section{RFCOMMENAIIONFOR FUNRAS}

Funerals for people who die of cholera - or of any other cause in a community affected by cholera - can contribute to the spread of an epidemic. If funeral feasts cannot be cancelled, meticulous handwashing with soap and clean water is essential before food is prepared and handled.

A designated health worker present at the funeral gathering can be helpful in supervising the use of hygienic practices.

\subsection{RECOMMENDAIONS FOR HANUING CORPSES}

It is important to ensure disinfection of corpses with a $0.5 \%$ chlorine solution (see Appendix 4). For transporting corpses of cholera patients, corpse-carriers should wear gloves; corpses should be carefully wrapped. 
Introduction

1 Detection

2. Confirmation

3. Response

4. Information

5. Treatment

6. Mortality

7. Hygiene

8. Community

9. Water

10. Food

11 Sanitation

12. Funeral

B. Surveillance

14. Partners

A.1

A.2

A.3

A.4

A.5

A.6

A.7

A.8

A.9
If possible, physical contact between the family and the corpse should be prevented. If this is not possible, the family must be made aware of the need to:

- wash hands with soap after touching the corpse;

- avoid putting hands in the mouth after touching the corpse;

- disinfect the dead person's clothing and bedding by stirring in boiling water for 5 minutes or by drying them thoroughly in the sun before and after normal washing.

People who wash and prepare the dead body must:

- wear gloves, apron and mask;

- clean the body with chlorine solution (0.5\%);

- fill the mouth and anus of the body with cotton wool soaked with chlorine solution;

- bandage the head to maintain the mouth shut;

- not empty the intestines. 


\section{B. Surveillance}

\section{KHMORDS}

INFORMATION FOR ACTION - DESCRIPTIVE EPIDEMIOLOGY

\section{ASSESSMENTOFTHEOUIRREAK}

\section{BASTCANAISSS}

1. Were data from previous outbreaks available and used to provide better understanding of the current outbreak?

2. Was there a good analysis of data by time, area, and high-risk group during the outbreak?

3. Was the information collected and analysed promptly enough to be used in monitoring the outbreak (see tips 13.1 and 13.2)?

4. Did health care workers understand the purpose of collecting information?

5. Did the patient file contain the essential basic information: patient's name, address, age, and sex, date of onset of symptoms, initial clinical assessment, evolution of illness, treatment received?

6. Was the information available and easily understandable to decisionmakers (e.g. members of the cholera coordination committee)? 


\section{Introduction}

1 Detection

2. Confirmation

3. Response

4. Information

5. Treatment

6. Mortality

7. Hygiene

8. Community

9. Water

10. Food

11 Sanitation

\section{Funeral}

B. Survellance

14. Partners

A.1

A.2

A.3

A.4

A.5

A. 6

A.7

A.8

A.9

\section{EPIDEMOIOGCAL INMSIIGAIION}

7. Has an epidemiological investigation of the outbreak been undertaken?

8. What kind of data analysis has been done: descriptive (person, place, time) or analytical (case study)? Have high-risk chan-nels of transmission been identified (water, food)?

9. Have the results of the investigation influenced the outbreak response?

10. What kind of difficulties arose during the investigation (logistics, contact with media, delay in organizing the investigation)?

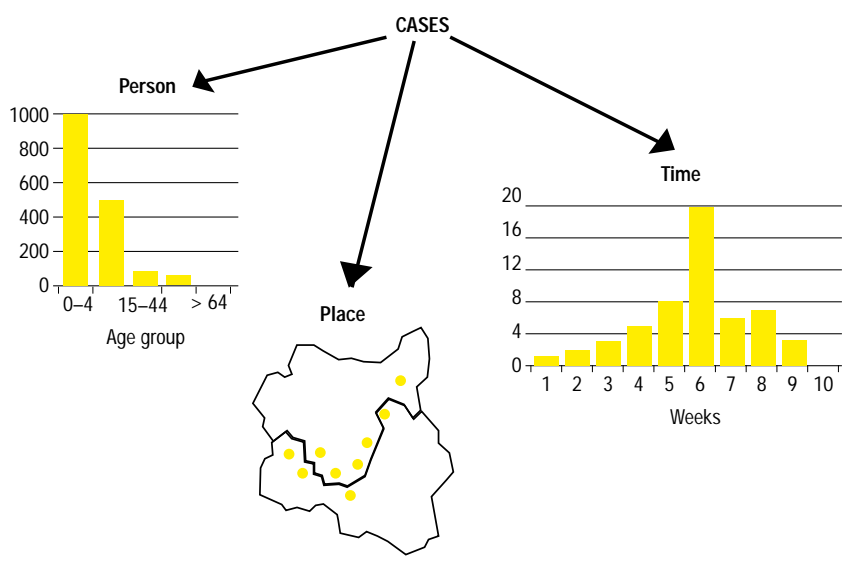

\section{CHOIFROUIBREAKRESPONSE}

58 


\section{LSFFUCOMMENISFORIMPROMEDPRHPARHDNESS}

Good information is part of good case management, and health care workers need to be trained in collecting basic information even when there is no outbreak. A case definition must be agreed and made widely known before the outbreak. (see 2.1)

A good routine surveillance system provides useful background information to:

- predict outbreaks;

- help with the epidemiological confirmation of an outbreak when a cluster of cases is discovered or when there is a sudden increase in cases or deaths from acute diarrhoeal syndrome.

Regular analysis of baseline data (person, place, time) is therefore valuable for adequate preparedness and for efficient monitoring of the cholera situation. Although a formal epidemiological investigation is not essential for cholera as the major routes of transmission and measures to be taken are well known, it may be valuable to identify high-risk activities or vehicles of transmission. A number of tools for this purpose, including the following, could usefully be developed in advance:

- form for data collection;

- protocol for casecontrol study;

- database for archiving the data (e.g. Epilnfo, Excel spreadsheet). 


\section{Introduction}

1 Detection

2. Confirmation

3. Response

4. Information

5. Treatment

6. Mortality

\section{Hygiene}

\section{Community}

9. Water

10. Food

11 Sanitation

12. Funeral

B. Survellance

14. Partners

A.1

A.2

A.3

A.4

A. 5

A.6

A. 7

A.8

A.9

\subsection{Descripine Fidemongr}

The important information is number of cases and deaths by area, by time period and by population sub-groups; calculation of attack and case-fatality rates allows the comparison of different areas and periods.

\subsection{CASE-FAIAITY RAIE}

[number of deaths/number of cases) $x$ 100] in a given period of time

When the case-fatality is high (> 1\%), it indicates:

- that case management is poor (check whether health care workers are sufficiently trained, supplies are lacking, or the health care centre is overwhelmed by the sudden increase in the number of patients);

- that people arrive too late at health care centres (establish community cholera treatment units, e.g. in schools, promote early use of ORS);

- bias of surveillance (deaths are better registered than cases). 


\subsection{ATtackraIE}

(number of cases/ population at risk) in a given period of time When attack rate is high, it indicates that:

- there is a common source of infection;

- the area is very crowded (as in urban areas, for example). 


\section{Introduction}

1 Detection

2. Confirmation

3. Response

4. Information

5. Treatment

6. Mortality

\section{Hygiene}

8. Community

9. Water

10. Food

11 Sanitation

12. Funeral

B. Surveillance

14. Partners

A. 1

A. 2

A. 3

A. 4

A. 5

A. 6

A. 7

A.8

A.9

\section{Involvement of international partners}

\section{KHMORDS}

PROJ ECT PROPOSALS - COORDINATION OF INTERNATIONAL PARTNERS

\section{ASSESSMENTOF"THEOUIBREAK}

1. What mechanisms were established to involve international partners (United Nations agencies, NGOs, international donors, private sector) in the outbreak response, in addition to health authorities (see tip 14.1)?

2. Has a list of needs that might be supported by international partners been established (see tip 14.2)?

3. Was there any formal mechanism for raising funds to support the outbreak response? Was a project proposal developed?

4. Which organization was coordinating the various partners involved in the outbreak response (see tip 14.3)?

5. Was there any strategic plan for the response, with specific tasks assigned to each partner (see tip 14.3)?

6. What was the role of WHO in the outbreak response (coordination, financial support, technical support)? At what level was WHO involved (HQ, regional level, country level)? 


\section{USHFULCOMMENSFORIMPROMADPRPARHDNESS}

A list of unfulfilled needs should be prepared before the outbreak.

Mechanisms must be established for ensuring good collaboration between volunteers from NGOs and national health care workers in the field.

Developing or maintaining good relationships with donors may be helped by:

- recording details of responsibilities in embassies or United Nations representations;

- organizing regular briefings;

- providing regular information on the epidemiological situation and on the effectiveness of the outbreak response.

\section{TIPS}

\subsection{INFORMAIONTO DONORS}

Concise information on the following topics is needed in order to persuade international partners to support the outbreak response:

- description of the outbreak:

$\checkmark$ magnitude

$\checkmark \quad$ geographical extent

$\checkmark \quad$ severity (case-fatality rate)

$\checkmark \quad$ evolution (epidemiological graphs to show improvement or deterioration of the situation) 


\section{Introduction}

1 Detection

2. Confirmation

3. Response

4. Information

5. Treatment

\section{Mortality}

7. Hygiene

8. Community

9. Water

10. Food

11 Sanitation

12. Funeral

B. Surveillance

14. Partners

A.1

A.2

A-3

A.4

A.5

A.6

A.7

A-8

A.9 $\checkmark \quad$ specificity of the outbreak (high attack rate, high case-fatality rate, other problems, e.g. floods, earthquake);

- needs for personnel and supplies;

- control activities undertaken and planned;

- updated inventory of staff and materials currently available.

\subsection{NFDS}

Needs may include the following:

- training and supervision of teams in the field;

- supplies;

- personnel (medical personnel, sanitarians, or health educators);

- support for epidemiological studies;

- support for laboratory examinations;

- support to ensure good coordination.

\subsection{CoOrdinamon}

In a complex emergency situation, coordination of the various international partners and NGOs involved in the response is a key issue. It might therefore be useful to make an inventory of support provided (see Appendix 9).

According to international partners, the support provided may be technical support alone or both financial and technical support.

\section{OHOIFRAOUIBREAKIRESPONEE}


Appendix I: Tool for evaluation

Appendix 2: Outline of the assessment report

Appendix 3: Essential rules in a cholera treatment unit

Appendix 4: Chlorine dilution according to use

Appendix 5: Methods for household water treatment

Appendix 6: Key messages for health education

Appendix 7: Preparation and use of 1\%chlorine solution to disinfect water

Appendix 8: Rules for safe preparation of food to prevent cholera

Appendix 9: Matrix for coordination of cholera control activities 
Appendix 1- Tool for evaluation

Introduction

1 Detection

2. Confirmation

3. Response

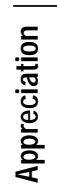

4. Information

\section{Treatment}

6. Mortality

7. Hygiene
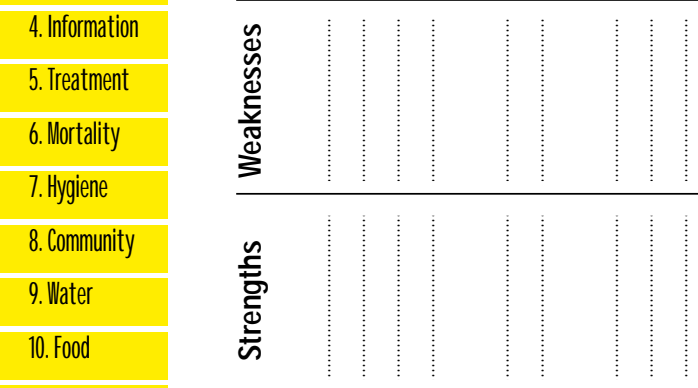

\section{Sanitation}

\section{Funeral}

\section{B. Surveillance}

\section{Partners}

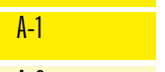

A.

A. 3

A.

A.

A.

A.

A. 8

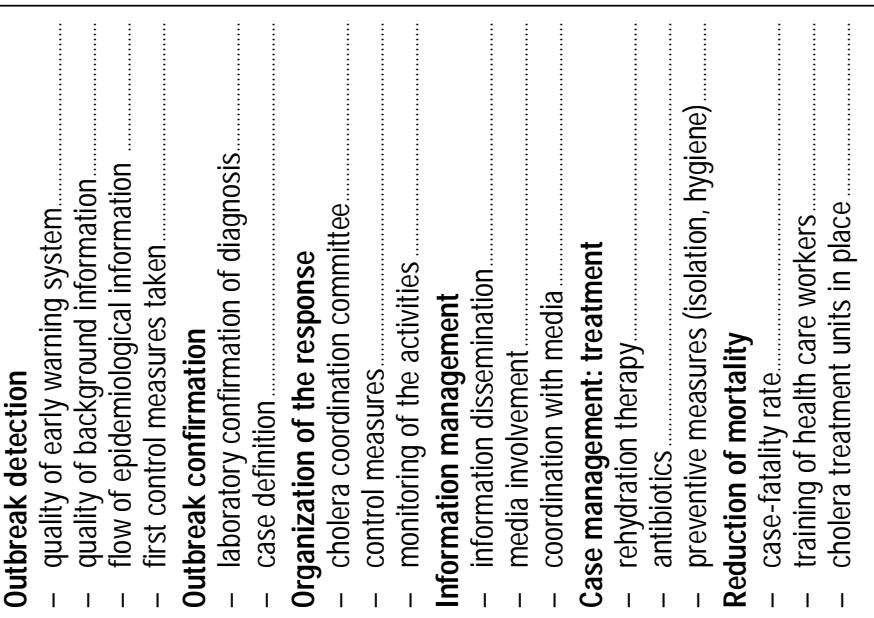

A. 9

\section{OHOIFRAOUIBREAKRESPONE}

66 



\section{Appendix 2 - Outline of the assessment report}

Introduction

1 Detection

2. Confirmation

3. Response

4. Information

5. Treatment

6. Mortality

7. Hygiene

8. Community

9. Water

10. Food

11 Sanitation

12. Funeral

B. Surveillance

14. Partners

A. 1

A. 2

A. 3

A. 4

A. 5

A.6

A.7

A.8

\section{EPIDEMOLOGCAL DESTRIPIIONOFTE HOHERA}

\section{STIUAIION}

The epidemiological description should include:

- cholera trends over time and the population groups regularly affected by the disease if the country has had previous cholera outbreaks;

- the nature of the recent outbreak in terms of time, places and people when it started, where, who was affected, what were the decisions taken to control the outbreak (see sections 1 and 2);

- the high-risk areas or population groups (who are the most affected) - attack rate and CFR by place, age, and sex (see section 13 for definitions); 
- a list of the risk factors overcrowding, sea shore in a tropical area, poor sanitation, lack of safe water, contaminated food, faecal-oral transmission risk, underlying factors such as malnutrition.

\section{ASSESSMENT Ofthe OUIBREAKRESPONSE}

The assessment of the response should address the following issues, stressing strengths and weaknesses:

- organization of the response (sections 3, 4 and 14);

- case management (sections 5, 6 and 7);

- surveillance and laboratory confirmation (sections 2 and 13);

- control of the environment (sections 9, 10, 11);

- control of the spread in the community (sections 8 and 12).

\section{Rroommenditons}

Short term, medium term, and long term.

\section{Conalsion}


Appendix 3 - Essential rules in a cholera treatment unit

Introduction

1 Detection

2. Confirmation

3. Response

4. Information

5. Treatment

6. Mortality

7. Hygiene

8. Community

9. Water

10. Food

11 Sanitation

12. Funeral

B. Surveillance

14. Partners

A.

A.

A. 3

A.

A. 5

A.

A.

A.8

A.9

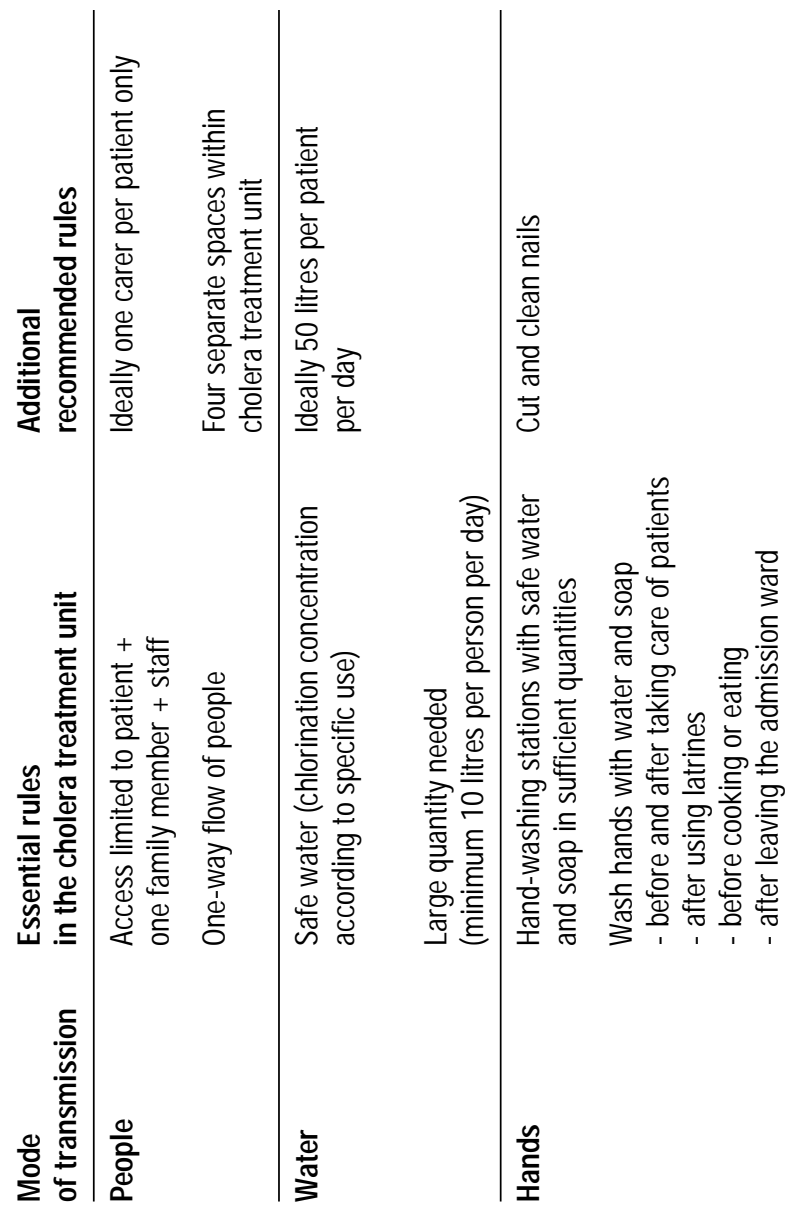

OHOIFRAOUIBREAKRESPONEE

70 


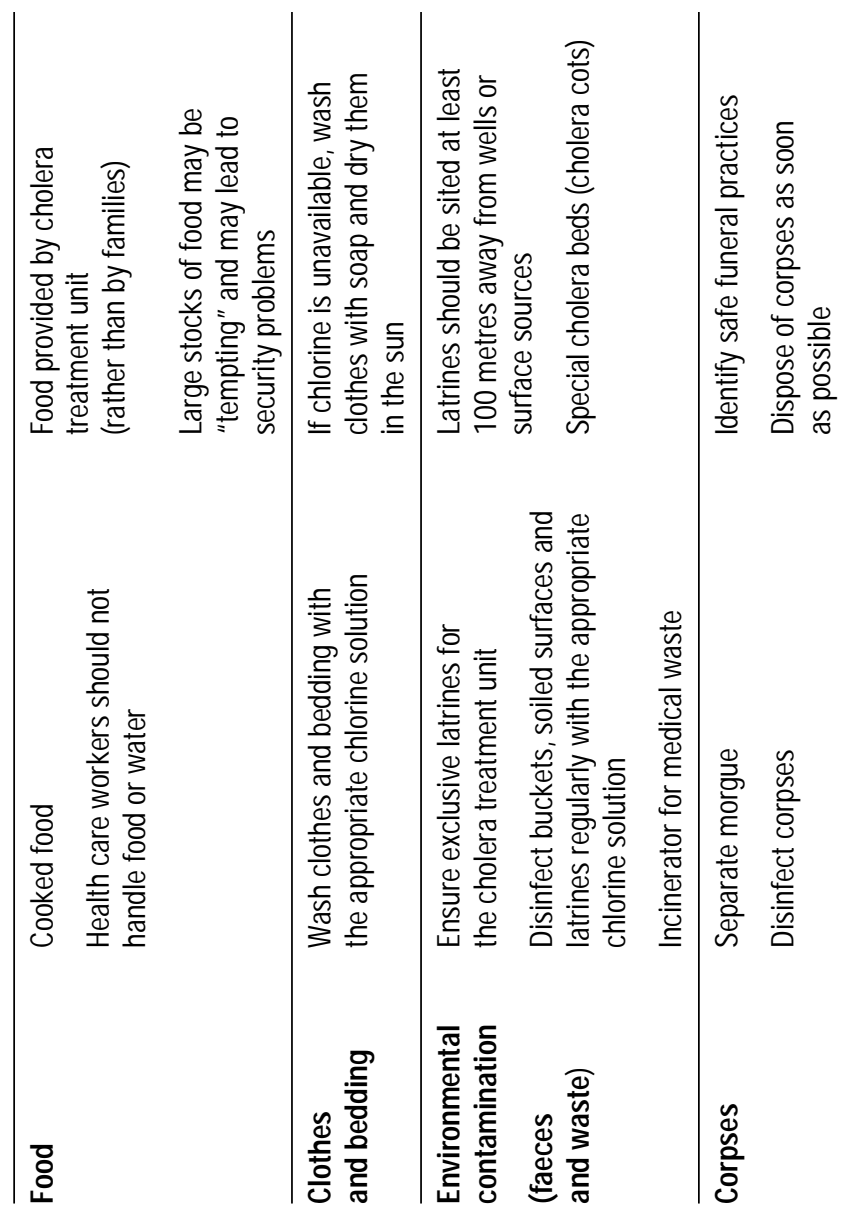




\section{Appendix 4 - Chlorine dilution according to use}

Introduction

1 Detection

2. Confirmation

3. Response

4. Information

5. Treatment

6. Mortality

7. Hygiene

8. Community

9. Water

10. Food

11 Sanitation

1. Funeral

B. Surveillance

14. Partners

A-1

A.2

A-3

A.4

A.5

A.6

A.7

A.8

A.9

Chlorine product

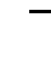


For desinfecting:

- gloved hands

- bare hands and skin

- floors

- clothing and equipment

- bedding prepare a $0.05 \%$ available chlorine solution

Add $100 \mathrm{ml}$ of bleach to 9.9 litres of water

or

Add 1 litre of 1:10 bleach solution to 9 litres of water (yields a 1:100 solution)

Add 16 grams or 1 tablespoon

to 10 litres of water

7 grams of half a tablespoon

dissolved in 10 litres of water 
Appendix 5 - Methods for household water treatment ${ }^{a}$

\begin{tabular}{|c|c|c|c|c|c|c|}
\hline $\begin{array}{l}\text { Introduction } \\
\text { 1Detection } \\
\text { 2. Confination }\end{array}$ & $3 \frac{5}{8}$ & 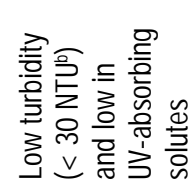 & z & z & 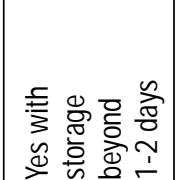 & 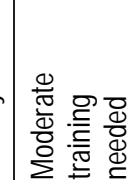 \\
\hline $\begin{array}{l}\text { 3. Response } \\
\text { 4. nitomaration }\end{array}$ & & & & 12 & & 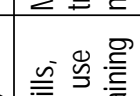 \\
\hline 5. Treatmentit & 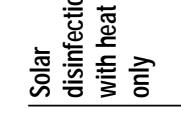 & $\frac{2}{2}$ & $z$ & $\xi$ & 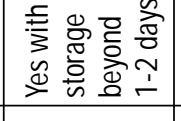 & 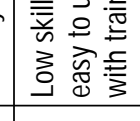 \\
\hline $\begin{array}{l}\text { 7. Hogene } \\
\text { 8. Community } \\
\text { 9.Vater }\end{array}$ & 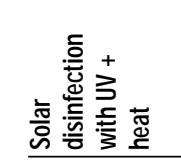 & 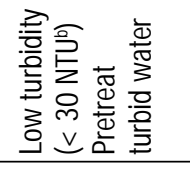 & $z$ & z & 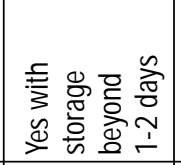 & 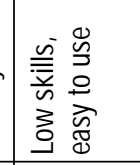 \\
\hline $\begin{array}{l}\text { 1. Food } \\
\text { 11 Santitation } \\
\text { D. Fineral }\end{array}$ & 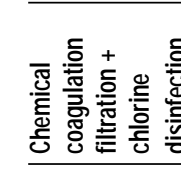 & $\frac{\varepsilon}{2}$ & $\underline{Z}$ & 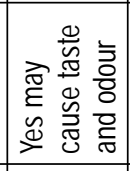 & 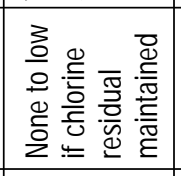 & 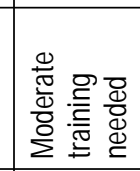 \\
\hline $\begin{array}{l}\text { 1. Suvellance } \\
\text { 1. Partners } \\
\text { A.1 }\end{array}$ & 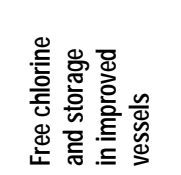 & 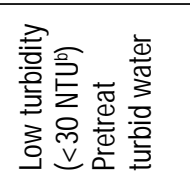 & $\underline{y}$ & 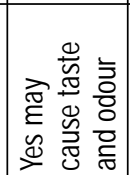 & 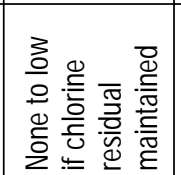 & 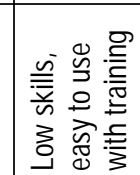 \\
\hline $\begin{array}{l}A .2 \\
A-3 \\
A-4\end{array}$ & 害 & $\frac{\mathscr{c}}{2}$ & $z$ & $z$ & 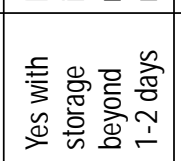 & 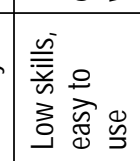 \\
\hline $\begin{array}{l}A .5 \\
A .6 \\
A .7 \\
A .8\end{array}$ & & 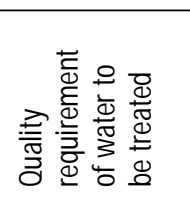 & 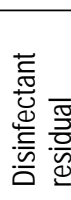 & 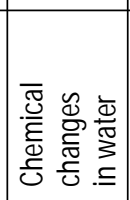 & 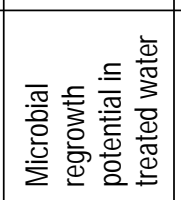 & 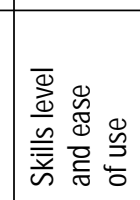 \\
\hline
\end{tabular}




\begin{tabular}{|c|c|c|}
\hline 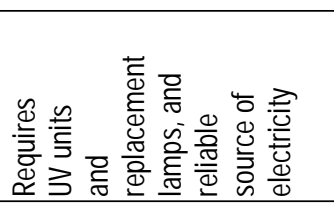 & $\begin{array}{l}\text { 오 } \\
\text { I }\end{array}$ & 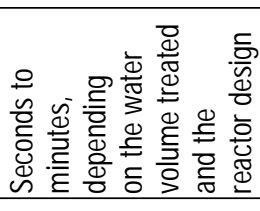 \\
\hline 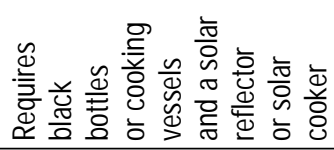 & $\begin{array}{l}\frac{8}{8} \\
\frac{8}{8} \\
\frac{1}{5} \\
\text { I } \\
\end{array}$ & 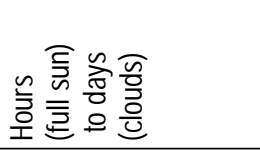 \\
\hline 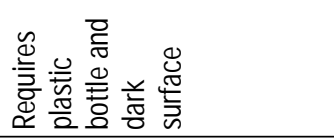 & 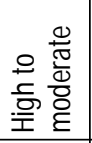 & 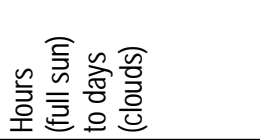 \\
\hline 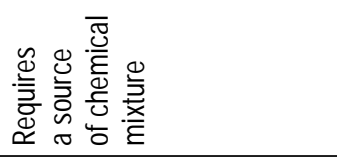 & 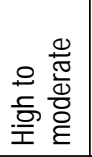 & 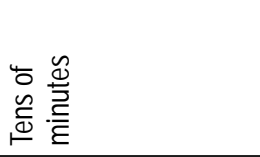 \\
\hline 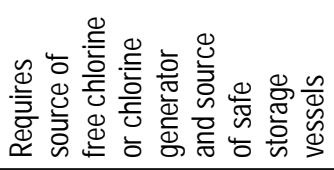 & 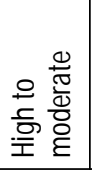 & 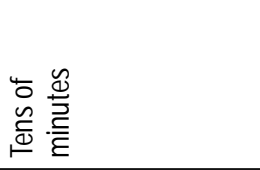 \\
\hline 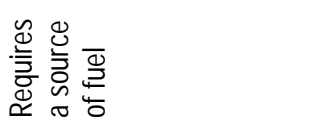 & $\begin{array}{l}\text { 옹 } \\
\end{array}$ & 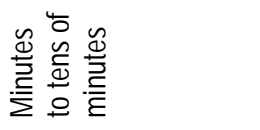 \\
\hline 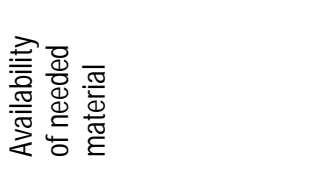 & $\frac{3}{\frac{3}{0}}$ & 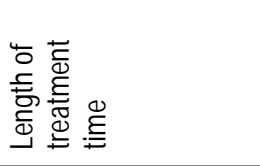 \\
\hline
\end{tabular}




\section{Appendix 6 - Key messages for health education}

Introduction

1 Detection

2. Confirmation

3. Response

4. Information

5. Treatment

6. Mortality

7. Hygiene

8. Community

9. Water

10. Food

11 Sanitation

12. Funeral

B. Surveillance

14. Partners

A-1

A. 2

A.3

A. 4

A. 5

A. 6

A. 7

A.8

A. 9
COOK YOUR FOOD - BOIL YOUR WATER - WASH YOUR HANDS

\section{Pergonal hidiene}

- Wash your hands with soap, ashes, or lime:

- before cooking,

- before eating and before feeding your children,

- after using the latrine or cleaning your children after they have used the latrine.

- Wash all parts of your hands - front, back, between the fingers, under nails.

- Use the latrine to defecate.

- Keep the latrine clean.

\section{Food}

- Cook raw food thoroughly.

- Eat cooked foods immediately.

- Store cooked food carefully in refrigerator.

- Reheat cooked food thoroughly.

- Avoid contact between raw food and cooked food. 
- Eat fruit and vegetable you have peeled yourself.

- Keep all kitchen surface clean.

- Wash your cutting board especially well with soap and water.

- Wash your utensils and dishes with soap and water. COOK IT - PEEL IT - OR LEAVE IT

\section{SAF DRINING-WIFR}

- Even if it looks clear, water can contain cholera germs.

- Boil, or add drops of chlorine to the water before drinking.

- Keep drinking-water in a clean, covered pot or bucket or other container with a small opening and a cover. It should be used within 24 hours of collection.

- Pour the water from the container - do not dip a cup into the container.

- If dipping into the water container cannot be avoided, use a cup or other utensil with a handle.

\section{Wís}

- Do not defecate or urinate in or near a source of drinking-water.

- Do not wash yourself, your clothes, or your pots and utensils in the source of drinking-water (stream, river, or water hole). 
Introduction

1 Detection

2. Confirmation

3. Response

4. Information

5. Treatment

6. Mortality

7. Hygiene

8. Community

9. Water

10. Food

11 Sanitation

1. Funeral

B. Surveillance

14. Partners

A-1

A.2

A.3

A.4

A.5

A.6

A.7

A.8

A.9
- Open wells must be covered when not in use to avoid contamination.

- The buckets used to collect water should be hung up when not in use - they must not be left on a dirty surface.

- The area surrounding a well or a hand pump must be kept as clean as possible.

- Get rid of refuse and stagnant water around a water source.

\section{FOR PFOPIE WIIHDIARRHOEA}

- The biggest danger of cholera is loss of water from the body.

- Do not panic, but act quickly.

- Drink a solution of oral rehydration salts made with safe (boiled or chlorinated) water.

- Go immediately to the health centre. Continue drinking as you go.

\section{TAKIng CARE OF PAIIFNIS}

- Wash your hands after taking care of patients, touching them, their stools, vomit, or clothes.

- Avoid contaminating a water source by washing a patient's clothes in it. 
- Stools and vomit from a cholera patient can be mixed with disinfectant (e.g. cresol).

- Disinfect the patient's clothing and bedding with a solution of chlorine $(0.05 \%)$ or by stirring them in boiling water or by drying them thoroughly in the sun before and after normal washing. 


\section{Appendix 7 - Preparation and use of 1\%chlorine solution}

Introduction

1 Detection

2. Confirmation

3. Response

4. Information

5. Treatment

6. Mortality

7. Hygiene

8. Community

9. Water

10. Food

11 Sanitation

12. Funeral

B. Surveillance

14. Partners

A. 1

A. 2

A. 3

A. 4

A. 5

A. 6

A. 7

A.8

A. 9

\section{Preparamonof 1\%ohorine siocksoution ${ }^{1}$}

To make 1 litre of the stock solution, mix the quantity shown of one of the following chemical sources with water and make up to 1 litre in a glass, plastic, or wooden container:

\begin{tabular}{lccr}
$\begin{array}{l}\text { Chemical } \\
\text { source }\end{array}$ & $\begin{array}{c}\text { \% available } \\
\text { chlorine }\end{array}$ & $\begin{array}{c}\text { Quantity } \\
\text { required }\end{array}$ & $\begin{array}{r}\text { Approximate } \\
\text { measures }\end{array}$ \\
\hline Bleaching powder & 35 & $30 \mathrm{~g}$ & 2 heaped tablespoons
\end{tabular}

\begin{tabular}{llll}
\hline Stabilized/tropical & $25 \quad 40 \mathrm{~g} \quad 3$ heaped tablespoons
\end{tabular}
bleach

\begin{tabular}{lrrr}
\hline High-test hypochlorite & 70 & $14 \mathrm{ml}$ & 1 tablespoon solution \\
\hline Liquid laundry bleach & 5 & $200 \mathrm{ml}$ & 1 teacup or 6-0z tin \\
\hline Liquid laundry bleach & 7 & $145 \mathrm{ml}$ & 10 tablespoons \\
\hline Javelle water & 1 & [is itself a 1\% stock solution] \\
\hline
\end{tabular}

A $1 \%$ solution contains $10 \mathrm{~g}$ of chlorine per litre $=10000 \mathrm{mg} /$ litre or 10000 ppm (parts per million).

1 tablespoon $=3$ teaspoons

Avoid skin contact with any of the chemical sources or the stock solution, and avoid inhaling chlorine fumes.

This stock solution should be fresh, i.e. made up every day and protected from heat and light. 


\section{to disinfect water}

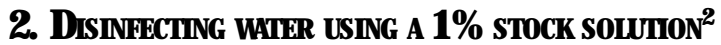

To produce an initial chlorine concentration sufficient to leave a free residual chlorine concentration of $0.4-0.5 \mathrm{mg} / \mathrm{litre}$ after 30 minutes:

1. Prepare a $1 \%$ chlorine solution.

2. Take 4 non-metallic water containers (e.g. 20 -litre plastic buckets) and put 10 litres of the water to be chlorinated in each one.

3. Using a syringe, add progressively greater doses of $1 \%$ chlorine solution to the containers:

- $1^{\text {st }}$ container: $1 \mathrm{ml}$

- $2^{\text {nd }}$ container: $1.5 \mathrm{ml}$

- $3^{\text {rd }}$ container: $2 \mathrm{ml}$

- $4^{\text {th }}$ container: $5 \mathrm{ml}$

4. Wait for 30 minutes, then use a comparator or test strip to measure the residual free chlorine concentration.

5. Choose the sample containing $0.4-0.5 \mathrm{mg} /$ litre of free residual chlorine.

6. Calculate the amount of $1 \%$ chlorine solution needed for the quantity of water to be treated.

${ }^{1}$ Source: UNICEF, 1986.

${ }^{2}$ Source: Delmas \& Courvallet, 1994. 


\section{Appendix 8 - Rules for safe preparation of food to prevent}

Introduction

1 Detection

2. Confirmation

3. Response

4. Information

5. Treatment

6. Mortality

7. Hygiene

8. Community

9. Water

10. Food

11 Sanitation

1. Funeral

B. Surveillance

14. Partners

A. 1

A. 2

A. 3

A.4

A. 5

A. 6

A. 7

A.8

A. 9

\section{COOK (RA) FOODS THOROUGH}

Fish, shellfish, and vegetables are often contaminated with cholera bacteria. Therefore, heat all the parts of the food to at least $70^{\circ} \mathrm{C}$. Do not eat uncooked foods unless they can be peeled or shelled.

\section{EAT COOKFD FODS IMMFDAAIFI}

When there is a delay between cooking and eating food, as when food is sold in restaurants or by street vendors, it should be kept over heat, at $60{ }^{\circ} \mathrm{C}$ or more, until served.

\section{STORE COOKHD FOODS CARFHUY}

If you must prepare foods in advance or want to keep leftovers, be sure to cool them to below $7{ }^{\circ} \mathrm{C}$ as soon as possible and then store them in a refrigerator or icebox below $7^{\circ} \mathrm{C}$. Cooked foods that have been stored must be thoroughly reheated before eating. Foods for infants should be eaten immediately after being prepared, and should not be stored at all.

\section{RHeAT COONHD FoOdS THOROUGY}

Proper storage at low temperature slows down the growth of bacteria but does not kill them. Once again, thorough reheating means that all parts of the food must reach at least $70^{\circ} \mathrm{C}$. Eat food while it is still hot. 
cholera

\section{ATOWCONTACT HEIUFANRANFOODS ANDCOOKED FOODS}

Safely cooked food can become contaminated through even the slightest contact with raw food (directly or indirectly through cutting surfaces or knife blades, for example).

\section{GroOsE FOODS PROCESSHD FOR SAFEIY}

Canned, acidic, and dried foods should be without risk.

\section{WGHHANDS RFPEAIFDY}

Wash hands thoroughly before preparing food and after every interruption - especially if you have to "change" or clean a baby, or have used the toilet or latrine. After preparing raw foods, such as fish or shellfish, wash your hands again before handling other foods.

\section{KEP ALL KITHENSURFACES QEAN}

Since foods are so easily contaminated, any surface used for food preparation must be kept absolutely clean. Think of every food scrap, crumb, or spot as a potential source of bacteria. Cloths used for washing or drying food, preparation surfaces, dishes, and utensils should be changed every day and boiled before reuse. Separate cloths that are used for cleaning the floors also require daily washing.

\section{UEE SAEE WIIRR}

Safe water is just as important for food preparation as for drinking. 
Appendix 9 - Matrix for coordination of cholera control

Introduction

\section{Detection}

2. Confirmation

3. Response

4. Information

5. Treatment

6. Mortality

\section{Hygiene}

8. Community

9. Water

10. Food

11 Sanitation

12. Funeral

B. Surveillance

14. Partners

A-1

A. 2

A. 3

A. 4

A. 5

A.

A. 7

A. 8

A. 9
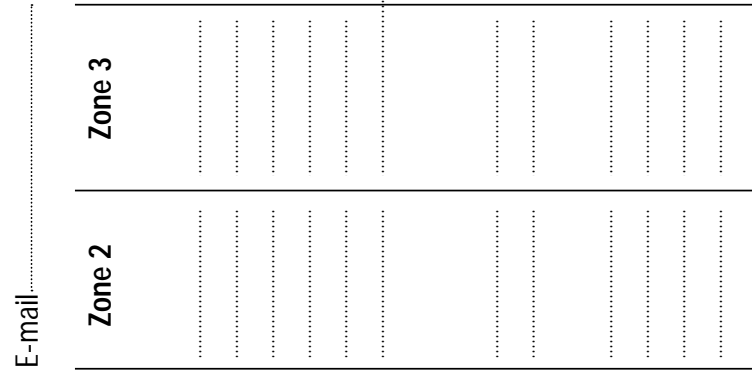

『

ก)
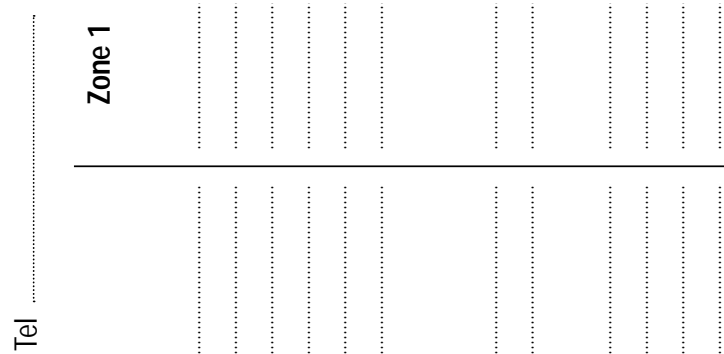

$\sum_{0}^{8} \frac{8}{8} \quad \frac{6}{8}$

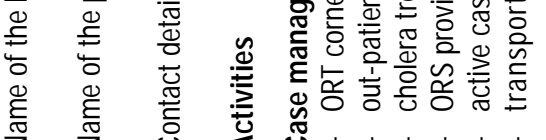

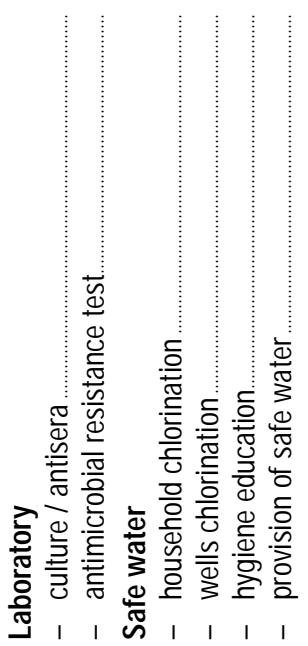


activities

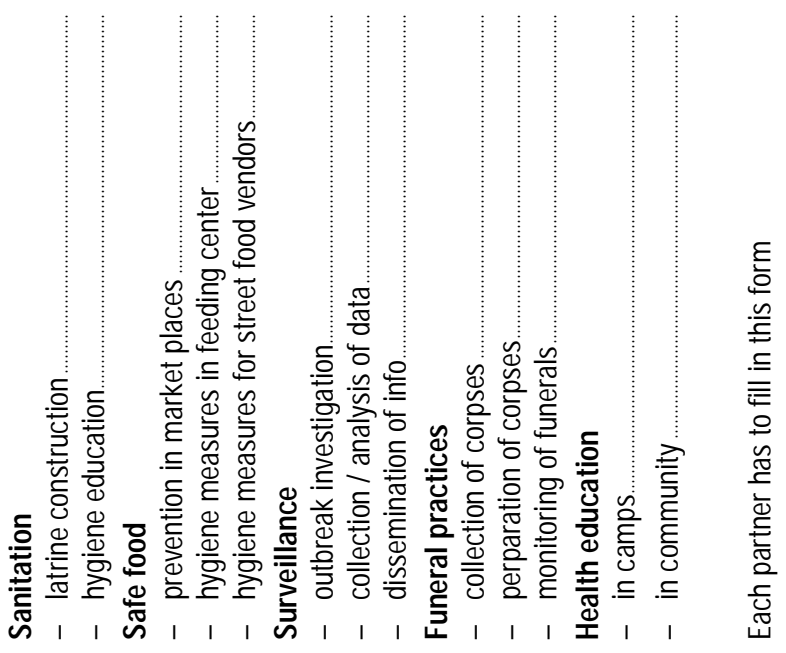




\section{Introduction}

1 Detection

2. Confirmation

3. Response

4. Information

5. Treatment

6. Mortality

7. Hygiene

8. Community

9. Water

10. Food

11 Sanitation

12. Funeral

B. Surveillance

14. Partners

A-1

A.2

A.3

A.4

A.5

A.6

A.7

A. 8

A.9

\section{References}

Barua D, Greenough B. Cholera. New York, Plenum, 1992.

BigotA et al. Prise en charge d'une épidémie de cholera [Management of a cholera outbreak]. Paris, Médecins Sans Frontières, 1995.

Bres P. Public health action in emergencies caused by epidemics a practical guide. Geneva, World Health Organization, 1986.

Delmas $G$, Courvalet $M$. Technicien sanitaire en situation précaire [Sanitarian in precarious situation]. Paris, Médecins Sans Frontières, 1994.

Detection and control of an epidemic of cholera: technical guidelines. Atlanta, GA, Centers for Disease Control and Prevention, 1995.

Ducel $G$ et al. Prevention of hospital-acquired infections. Geneva, World Health Organization, 2002.

Fact sheets on environmental sanitation. Geneva, World Health Organization, 1996.

Guidelines for cholera control. Geneva, World Health Organization, 1993.

Guidelines for the collection of clinical specimens during field investigation of outbreaks. Geneva, World Health Organization, 2000 (WHO/CDS/CSR/EDC/2000.4)

Handbook for emergency field operations. Geneva, World Health Organization, 1999 (EHA/FIELD/99.1).

\section{6}


Hanquet G. Refugee health - an approach to emergency situations. London, Médecins Sans Frontières/Macmillan, 1997.

Heymann DL, ed. Control of communicable diseases manual. Washington, DC, American Public Health Association, 2004.

Kindhauser MK, ed. Global defence against the infectious disease threat. Geneva, World Health Organization, 2003.

Laboratory methods for the diagnosis of epidemic dysentery and cholera. Atlanta, GA, Centers for Disease Control and Prevention, 1999.

Perrin P. Guerre et santé publique [War and public health]. Genève, Comité International de la Croix-Rouge, 1995.

Sack D. Cholera checklist. Arlington, VA, PRITECH, 1991.

Safe water systems for the developing world - a handbook for implementing household-based water treatment and safe storage projects. Atlanta, GA, Centers for Disease Control and Prevention, 2000.

Sobsey M. Managing water in the home: accelerated health gains from improved water supply. Geneva, World Health Organization, 2002 (WHO/SDE/ WSH/02.07).

The treatment of diarrhoea - a manual for physicians and other senior health workers. Geneva, World Health Organization, 1995 (WHO/CDR/95.3).

WHO recommended strategies for prevention and control of communicable diseases. Geneva, World Health Organization, 2001 (WHO/CDS/CPE/ SMT/2001.13).

Wisner B, Adams J, eds. Environmental health in emergencies and disasters: a practical guide. Geneva, World Health Organization, 2002. 



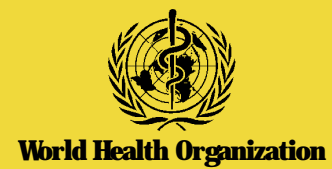

For more information, please contact:

GOBAL TASKFORCEONAHARA CONIRO

World Health Organization CH-1211 Geneva 27

Email: cholera@who.int www.who.int/cholera 